\title{
Análise da distribuição física e roteirização em um atacadista
}

\author{
Leandro Minoru Enomoto \\ Renato da Silva Lima \\ UNIFEI
}

\begin{abstract}
Resumo
O objetivo deste trabalho é analisar a distribuição física em uma empresa do setor atacadista, com especial atenção ao seu processo de roteirização e programação de veículos. Para tanto, foi realizado um estudo de caso em um grande atacadista, localizado na região Sul de Minas Gerais, no qual se procurou relacionar os aspectos práticos que cercam estas rotinas operacionais, baseados na literatura técnica especializada. Como conclusão geral, pode-se afirmar que a empresa, apesar de utilizar diversos conceitos e ferramentas de apoio em seu processo de distribuição física, ainda é refém da falta de informações em processos operacionais tecnicamente simples [como as distâncias viárias exatas entre os clientes]. Como conseqüência, observa-se que o processo acaba por ser racionalizado e não otimizado e, em diversas etapas, excessivamente dependente da experiência prática do profissional envolvido.
\end{abstract}

\section{Palavras-chave}

Distribuição física, roteirização e programação de veículos, atacadista.

\section{Analysis of physical distribution and routing in a wholesaler}

\begin{abstract}
The objective of this work is to analyze the physical distribution in a company of the wholesale market, with special attention on its vehicle routing and scheduling process. In this manner, a case study in a wholesale, placed in the south of Minas Gerais state, was carried out. This study related the practical aspects of the operational routines established in literature specialized technique. As general conclusion, it can be affirmed that the company despite using diverse concepts and tools to support its physical distribution processes is still hostage of the lack of information in technical simple operational processes, as the accurate road distances between the customers. Consequently, it is observed that the process is rather rationalized other than optimized and, in diverse stages, excessively dependent of practical experience of the involved personnel.
\end{abstract}

Key words

Physical distribution, vehicle routing and scheduling, wholesaler. 


\section{INTRODUÇ̃̃O}

O planejamento de sistemas de distribuição física de produtos se torna cada vez mais um dos principais desafios para os pesquisadores que atuam na área de transporte, devido à complexidade matemática das soluções dos problemas e pelas decisões tomadas. Conforme Naruo (2003), as decisões de transportes e de distribuição física em geral se expressam em uma variedade de formas; entre as principais, estão a roteirização e a programação de veículos. A partir de um sistema já dimensionado, com demanda, ofertas e os recursos necessários conhecidos, a roteirização e programação de veículos apresentam enfoque altamente operacional, em que a busca por melhores trajetos se torna um problema diário de decisão.

Diversas aplicações práticas podem ser citadas, como: entrega em domicílio de produtos comprados em lojas de varejo ou Internet, distribuição de jornais, distribuição de bebidas em bares, etc. (NOVAES, 2004). O problema de roteirização pode ser classificado como a forma de determinar percursos ótimos para uma frota de veículos estacionada em um ou mais domicílios, de forma a atender um conjunto de clientes geograficamente dispersos (BODIN et al., 1983). Com relação à programação ou seqüenciamento de um veículo, Chih (1987) caracteriza o problema como uma seqüência de pontos que um veículo precisa percorrer, tendo a condição adicional de terem horários preestabelecidos de chegada e partida.

Na prática, observa-se que as soluções apresentadas para este ambiente operacional muitas vezes são executadas manualmente ou através de técnicas simples. Segundo Chih (1987) e Bose (1991), a maioria das empresas no Brasil empregam profissionais especialmente treinados para a execução da atividade de roteirização, que separam e agrupam os pedidos enviados à empresa baseados na sua experiência, o que, apesar de simplificar o processo de cálculo, pode levar a soluções que estejam distantes das soluções ótimas

Situações como essa ocorrem também com freqüência no setor atacadista, que se apresenta como um importante intermediário nos canais de distribuição, devido às funções desempenhadas perante varejistas e indústrias. Soma-se a isso o crescimento acelerado do setor, vinculado a outros fatores e restrições como: aumento das áreas de atendimento, alta concentração regional, horários de atendimento (janelas de atendimento), vias de acesso, limitações de tamanho de veículos, tipos de produtos, fracionamento de produtos etc. Assim, tem-se um ambiente operacional complexo, em que as variáveis envolvidas podem provocar aumento de custos e perda de eficiência operacional no sistema de distribuição física.

Neste contexto, o objetivo deste trabalho é analisar a distribuição física em uma empresa do setor atacadista, com especial atenção ao seu processo de roteirização e programação de veículos. Para tanto, foi realizado um estudo de caso em um grande atacadista, localizado na região Sul de Minas Gerais. Cabe ressaltar que o trabalho não tem por objetivo discutir os aspectos matemáticos e a modelagem da roteirização, e sim abordá-la no contexto da distribuição física de modo mais geral, ou na gestão dessa distribuição física.

O trabalho está estruturado da seguinte maneira: após esta breve introdução, apresentam-se o referencial teórico do trabalho (Distribuição Física, Transportes e Zoneamento, Roteirização e Comércio Atacadista). A seguir, aborda-se a metodologia de pesquisa, seguida das evidências do estudo de caso na seção 5. A última seção traz as conclusões do trabalho, seguidas da lista com as referências bibliográficas utilizadas.

\section{DISTRIBUIC̣̃̃O FÍSICA}

A distribuição de produtos é uma das principais atividades das empresas, pois define o sucesso no processo de atendimento aos seus clientes. Um bom planejamento desta atividade pode criar condições para alcançar a eficiência e a confiabilidade no serviço prestado pela empresa, garantindo a satisfação dos clientes e a redução dos seus custos (BOTELHO, 2003). A distribuição deve ser garantida em todos os componentes da cadeia de abastecimento no prazo e com a qualidade determinada. É a distribuição física que efetua o vínculo entre a empresa e seus clientes (BOWERSOX; CLOSS, 2001). Para Demaria (2004), o profissional de logística deve se preocupar em garantir a disponibilidade dos produtos requeridos pelos clientes à medida que eles os solicitem e também em assegurar que isso seja feito a um custo razoável.

Segundo Bose (1990), a distribuição física compreende o transporte do produto do centro produtor ao consumidor diretamente ou via depósitos. Assim, os profissionais da distribuição operam elementos como depósitos, veículos, estoques, equipamentos de carga e descarga, entre outros. Enomoto (2005) cita que a distribuição física está sofrendo grandes transformações à medida que as empresas adotam sistemas de gestão de logística e operações globais, exigindo do mercado de transportes uma melhoria contínua para que seja atendida a demanda crescente.

Neste contexto, conforme Ballou (2001) e Galvão (2003), o gerenciamento da distribuição física se dá em três níveis: estratégico, tático e operacional. Os problemas de roteirização e programação são tratados na fase operacional do sistema de distribuição. Assim, para que a otimização dos roteiros dê resultados satisfatórios é preciso que o sistema tenha sido bem planejado e bem dimensionado nos níveis estratégicos e táticos, altura em que devem ser definidas 
questões como, por exemplo, a composição da frota e o zoneamento (divisão da região de distribuição em zonas de atendimento) (GALVÃO, 2003).

A seguir, são detalhados alguns dos fatores relevantes para a distribuição física e que serão posteriormente considerados no estudo de caso: transporte e zoneamento, roteirização e programaçnao de veículos, e softwares de roteirização. volume e cargas pesadas pelo seu próprio peso. Tanto a falta de capacidade quanto o excesso retratam um problema para a empresa. O primeiro implica no não atendimento de clientes e o segundo no desperdício de recursos.

Outra restrição importante no dimensionamento do sistema é a máxima jornada de trabalho dos tripulantes (motoristas e ajudantes). Acima de um determinado número de horas de trabalho por dia, o desgaste físico e psíquico torna-se excessivo, prejudicando o empregado e os níveis de desempenho do próprio sistema. Observa-se, também, que a jornada de trabalho máxima é determinada por lei e por acordos específicos com os sindicatos. Ocorre, assim, uma restrição temporal no dimensionamento e na operação do sistema.

\section{Transporte e Zoneamento}

Novaes (1989), Valente et al. (2003) e Galvão (2003) apresentam as características básicas da coleta e distribuição de carga no transporte rodoviário:

- Uma região geográfica é dividida em zonas, cujos contornos podem ser rígidos ou, em alguns casos, podem sofrer alterações momentâneas para acomodar diferenças de demanda em regiões contíguas;

- Para cada zona é alocado um veículo, com uma equipe de serviço, podendo ocorrer outras situações (mais de um veículo por zona, por exemplo);

- A cada veículo é designado um roteiro, incluindo os locais de parada, pontos de coleta ou entrega, atendimento de serviços, a equipe que deverá atendê-los, entre outros;

- O serviço deverá ser realizado dentro de um tempo de ciclo predeterminado. No caso de coleta / entrega urbana, o roteiro típico inicia-se pela manhã e se encerra no fim do dia (ou antes, se o roteiro for totalmente cumprido). Nas entregas regionais, o ciclo pode ser maior;

- Os veículos são despachados a partir de um depósito, onde se efetua a triagem da mercadoria (ou serviço) em função das zonas. Nos casos em que há mais de um depósito, o problema poderá ser analisado de forma análoga, efetuando-se, para isso as divisões adequadas da demanda e/ou área geográfica a ser atendida. A localização e utilização dos depósitos precisam ser programadas.

Valente et al. (2003) acrescentam que alguns condicionantes físico-temporais devem ser examinados e incorporados à metodologia de análise e dimensionamento, de forma a se obter resultados mais realistas. Um primeiro aspecto a se considerar é o da capacidade física dos veículos de coleta/distribuição. Dependendo das características físicas da carga (peso/volume) e da capacidade do veículo, é possível ocorrer, em certas ocasiões, a superlotação do caminhão. Logo, é importante determinar o tipo de carga a ser transportada. Cargas leves são geralmente limitadas pelo seu
Outro problema que surge no dimensionamento de sistemas de coleta/distribuição operando em regiões relativamente grandes é o desequilíbrio em termos de produção entre os veículos que atendem zonas próximas ao depósito e os que atendem zonas mais afastadas. De modo geral, o problema de zoneamento ou particionamento envolve criar grupos de elementos baseados em proximidade ou medidas de similaridade. Novaes (1989) cita que esse conceito visa tirar vantagem das características morfológicas das redes de transporte, especialmente em vias arteriais com direções bem definidas e vários pontos a serem atendidos por um único veículo. A determinação precisa dos contornos das zonas de distribuição constitui um problema relativamente complexo, pois envolve conceitos topológicos, operacionais, urbanísticos e viários. Na prática, os serviços logísticos de distribuição física de produtos têm as zonas dimensionadas e delimitadas através de procedimentos empíricos, baseadas na experiência contínua do próprio processo operacional.

\section{Roteirização e Programação de Veículos}

Para Cunha (2000) e Vieira (1999) a roteirização é o processo para a determinação de um ou mais roteiros ou seqüências de paradas a serem cumpridos por veículos de uma frota, tendo por objetivo utilizar um conjunto de pontos geograficamente dispersos, em locais predeterminados, que necessitam de atendimento. A roteirização pode ser caracterizada por $n$ clientes (representados numa rede de transportes por nós ou arcos) que deverão ser servidos por uma frota de veículos, sem apresentarem restrições ou a ordem em que deverão ser atendidos. Deste modo, representa uma configuração espacial do movimento do veículo em uma rede (BOSE, 1990). A programação, por sua vez, refere-se à definição dos aspectos temporais de um ou mais roteiros, mais especificamente aos horários de cada uma das tarefas ou eventos importantes, ou ainda a prioridade no atendimento ou cumprimento de um horário. Representa assim uma configuração temporal (BOSE, 1990; CUNHA, 1997). 
Considerando Bodin et al. (1983), Assad (1991) e Laporte et al. (2000), observa-se que as principais características dos problemas de roteirização e programação são: tamanho da frota disponível, tipo de frota, garagem dos veículos, natureza da demanda, localização da demanda, características da rede, restrições de capacidade dos veículos, requisitos de pessoal, tempos máximos de rotas, operações envolvidas, custos, objetivos e outras restrições (variáveis do problema).

Embora os problemas de roteirização de veículos apresentem variações, pode-se de um modo geral reduzi-los segundo a origem e destino do trajeto e segundo o tipo de modelagem (nó ou arco). Quanto à origem e destino, há o problema de se encontrar um trajeto em uma rede onde o ponto de origem seja diferente do ponto de destino, em que os pontos de origem e de destino são coincidentes, ou em que existam múltiplos pontos de origem e de destino. Adicionalmente, segundo Cunha (1997), com relação ao ambiente de distribuição, os problemas reais de roteirização podem ser divididos em dois grupos:

- Roteirização em meio urbano, em que tanto os atendimentos quanto a base localizam-se na mesma área urbana; os percursos do roteiro são predominantemente urbanos;

- Roteirização intermunicipal, na qual os atendimentos localizam-se em municípios distintos da base e entre si; os percursos do roteiro são predominantemente rodoviários.

Em geral, os problemas de roteirização em meio urbano tendem a ser mais complexos do ponto de vista da sua natureza combinatória, uma vez que há um número maior de alternativas de caminhos e, conseqüentemente, de roteiros viáveis. Adicionalmente, há restrições à circulação de veículos, e incertezas quanto aos tempos de viagem. $\mathrm{Na}$ distribuição intermunicipal (rodoviária), as distâncias entre pontos de atendimento, em geral, diferentes cidades, são geralmente longas, e podem ser determinadas a partir de dados facilmente acessíveis e disponíveis da malha rodoviária de interesse. A densidade da malha rodoviária é baixa face às distâncias a serem percorridas. Além disso, são menores as incertezas associadas às restrições e condicionantes de tráfego.

\section{Classificação dos problemas de roteirização}

A classificação dos problemas de roteirização segue aqui a proposta por Bodin et al. (1983), já tomada como referência por diversos autores (CUNHA, 2003; DINIZ, 2000; NARUO, 2003; PELIZARO, 2000). Segundo Cunha (2003), apesar de o trabalho ser relativamente antigo, ainda representa umas das principais referências bibliográficas sobre o assunto. A divisão proposta pelos autores considera as restrições geográficas e espaciais, dividindo assim os problemas em três grupos:

- Problemas de roteirização pura:

São problemas espaciais que não consideram as variáveis temporais ou precedências entre as atividades para elaboração dos roteiros de coleta e/ou entrega. Em alguns casos tem-se apenas a restrição de comprimento máximo da rota. Nesse tipo de problema existe um conjunto de nós e/ou arcos para serem atendidos que formarão uma seqüência de locais (rota), buscando alcançar a minimização do custo total de transporte.

- Problemas de programação de veículos e tripulações

Os problemas de programação podem ser considerados como problemas de roteirização com restrições adicionais relacionadas ao tempo, quando várias atividades precisam ser executadas. Este tipo de problema pode ser dividido em dois casos: Programação de veículos e Programação de tripulações. O foco do primeiro está na sequiência das atividades para os veículos no espaço e no tempo e do segundo na movimentação da tripulação no espaço e no tempo.

- Problemas de roteirização e programação

Os problemas de roteirização e programação envolvem relações de precedência entre as atividades envolvidas e também restrições de janelas de tempo (horário de atendimento e outros). Podem ser considerados como uma combinação de problemas de roteirização e programação. São problemas que freqüentemente surgem na prática e representam aplicações do mundo real. Apresentam restrições mais realistas, onde cada parada pode ter volumes a serem coletados ou entregues. Uma importante variação desse problema é o Problema de roteirização e programação de veículos com janelas de tempo (PRPVJT), onde os pontos para atendimento têm uma ou mais janelas de tempo durante o qual o serviço pode ser executado.

\section{Softwares de roteirização}

Softwares de roteirização são sistemas computacionais que através de algoritmos, geralmente heurísticos, e uma apropriada base de dados apresentam soluções para os problemas de roteirização e programação de veículos com resultados satisfatórios, consumindo tempo e esforço de processamento pequenos quando comparados aos dos tradicionais métodos manuais (MELO; FILHO, 2001). Segundo Novaes (2004), hoje se dispõe no mercado de um número razoável de softwares de roteirização, que ajudam as empresas a planejar e programar seus serviços de distribuição física. Atualmente, estas ferramentas consideram um grande número de restrições ou condicionantes, que tornam possível a obtenção de modelos bastante precisos. Além disso, são dotados de muitos recursos de visualização gráficos e de relatórios que auxiliam o usuário na tomada de decisão.

Conforme cita Cunha (1997), embora a quase totalidade dos desenvolvedores de softwares de roteirização mantenha 
em sigilo os algoritmos de solução utilizados, a análise de resultados obtidos para algumas instâncias específicas de problemas permite inferir que são heurísticas simples, que produzem soluções viáveis e, em geral, de boa qualidade para problemas de grande porte, em reduzido tempo de processamento. Pelizaro (2000) e Naruo (2003) afirmam que, geralmente, os sistemas de roteirização e programação têm sempre a mesma saída: para cada veículo ou tripulante, uma rota e uma programação são providenciadas. No entanto, vale destacar a ressalva de Couto (2004): "as heurísticas existentes para resolver os problemas das rotas e entregas, nos softwares especializados no mercado, tendem a ser muito generalistas e não costumam gerar resultados satisfatórios".

que se tenha uma representação analítica adequada da rede viária e que se disponha de uma base de dados georeferenciados dos endereços dos clientes. No entanto, essas bases nem sempre estão disponíveis no mercado e, quando estão, muitas vezes se encontram incompletas, imprecisas e/ou desatualizadas.

\section{COMÉRCIO ATACADISTA}

Segundo Berman (1996), as atividades atacadistas são definidas como as de estabelecimentos que vendem a varejistas, compradores industriais, institucionais e comerciais, mas não em quantidades adequadas aos consumidores finais. As principais funções do atacado são melhorar a coordenação entre a produção e pontos de consumo, suprindo lacunas, tentando reduzir irregularidades de oferta e demanda, e prover diretamente o diferencial dos serviços esperados pelos consumidores e os oferecidos pelos fabricantes. Segundo Neves (1999), o atacado permite aos seus

Observa-se que o interesse e a demanda por softwares comerciais disponíveis no mercado têm crescido muito nos últimos anos. Entre as razões, destacam-se as exigências dos clientes com relação às restrições cada dia maiores, como prazos, datas e horários de atendimento; problemas de trânsito, circulação e estacionamento de veículos nos centros urbanos; aumento da competição pelo mercado e a busca de eficiência, redução de estoques e aumento da freqüência de entregas.

Para Melo e Filho (2001) a prática mostra que sistemas mal implantados ou mal gerenciados provocam prejuízos e problemas. Estes sistemas geram significativos custos, tanto na aquisição, como na manutenção de suas bases de dados, o que pode ser caracterizado como um dos pontos negativos à sua utilização. O que se percebe é que a maioria dos casos de insucesso é ocasionada por falta de um bom planejamento e gerenciamento de implantação, por "empolgação" para se comprar um software recém-lançado, por falta de orientação e até mesmo por falta de uma maior quantidade de informações em relação às características dos produtos disponíveis no mercado.

Cabe ressaltar ainda novas tendências e novos desafios que se apresentam para o setor. Os softwares, que outrora focavam o planejamento da distribuição dentro de um prazo mínimo de 24 horas, têm como tendência atual a execução da programação em tempo real (NOVAES, 2004). Outra meta das empresas fornecedoras é tornar os softwares mais fáceis de ser utilizados pelos operadores. Para isso, é necessário consumidores comprar diversos produtos em menores quantidades, com menor número de operações. Uma vez que a distribuição dos produtos é bastante complexa, o setor atacadista tem aumentado o grau de especialização constantemente, em resposta às demandas mais específicas de serviços por parte de seus consumidores (o varejo) e fornecedores (a indústria).

Entre os serviços prestados pelos atacadistas aos seus fornecedores, destacam-se: a cobertura de mercado, onde os atacadistas, por estarem mais próximos aos consumidores (varejistas), têm condições de identificar as necessidades em seus territórios; o contato de vendas; a estocagem; o processamento de pedidos; o fornecimento de informações de mercado; e o suporte aos consumidores. Já para os serviços prestados pelos atacadistas aos seus clientes (varejistas), observa-se a função de disponibilidade de produtos, ou seja, em função de sua proximidade, conseguem oferecer a pronta entrega dos produtos requeridos; a conveniência no suprimento, simplicidade nos pedidos e a facilidade de ter apenas um fornecedor; ofracionamento, venda dos produtos em menores quantidades; a função de crédito e financeira, podendo oferecer crédito e prazo para o pagamento, facilitando o capital de giro do varejista e reduzindo a necessidade de estoque; e o suporte técnico.

Os principais tipos de atacadistas classificados por Bowersox e Cooper (1992), Stern et al. (1996), Berman (1996) e Neves (1999), com base em critérios de propriedade sobre os produtos, são: 
- Fabricantes atacadistas - Os fabricantes executam as atividades atacadistas e controlam os produtos até que sejam vendidos. Sua rentabilidade é determinada através da diferença entre o custo cobrado pelo serviço de distribuição e o preço da compra (preço de transferência);

- Atacadistas especializados - Compram (adquirem os direitos de propriedade) e realizam todas as atividades atacadistas. Pode-se dizer que são os principais em termos de faturamento;

- Atacadistas de Balcão e Auto-serviço: são bastante próximos aos especializados, porém não realizam vendas a crédito nem entrega;

- Agentes, intermediários e comissionados-Normalmente, estes agentes não compram os produtos e serviços. Assumem algumas das funções e recebem comissões por elas.

Neves (1999) afirma que é possível eliminar os intermediários (entre eles o atacado) da distribuição, mas é impossível eliminar suas funções. A dúvida que fica para os fabricantes é se esses conseguem desempenhar as funções dos atacados de maneira mais eficiente, integrando-se verticalmente em vendas, depósito e outras estruturas de distribuição. As mesmas decisões valem para o varejo (STERN et al., 1996).

A partir dessa base conceitual, as próximas seções apresentam o estudo de caso realizado na atacadista selecionada, sendo as evidências encontradas analisadas e comentadas na seção Evidências do caso.

\section{METODOLOGIA DE PESQUISA}

A abordagem adotada para este trabalho foi a qualitativa, pois ela procura conhecer e compreender, a partir das informações obtidas na fundamentação teórica, como a distribuição física e a roteirização estão sendo abordados no ambiente operacional. Os métodos qualitativos são úteis para fenômenos amplos e complexos, em que o conhecimento existente é insuficiente para permitir a proposição de questões causais ou quando o fenômeno não pode ser estudado fora do contexto no qual ele naturalmente ocorre (BONOMA, 1985).

Com relação ao método, o estudo de caso foi selecionado, pois se demonstrou mais adequado aos objetivos da pesquisa. Einsenhardt (1989) descreve o método como uma estratégia de pesquisa focada no entendimento da dinâmica de uma organização. Estas características são encontradas nesta pesquisa, cuja natureza exploratória busca a captação das perspectivas e interpretações das pessoas e, desta forma, compreender o ambiente e esclarecer os conceitos, relacionando-os ao ambiente, para validar o estudo e definir seu problema.
A empresa (objeto de estudo) selecionada para a condução do estudo de caso foi um grande atacadista localizado no sul de Minas Gerais, sexto maior atacadista no mercado brasileiro (NEVES, 1999), que atua nos Estados de Minas Gerais e São Paulo. A empresa é composta por um centro de distribuição (CD), situado em Poços de Caldas - MG, com $15.000 \mathrm{~m}^{2}$ de área de armazenagem e responsável pela distribuição de 4.000 produtos industrializados. O público alvo da empresa são pequenos e médios clientes varejistas, que estão distribuídos geograficamente em 154 praças, que podem ser cidades, municípios ou distritos. Estas praças estão agrupadas em 15 zonas, denominas pela empresa de microrregiões de trabalho.

\section{preocupação principal da empresa é a entrega no tempo correto em rimento de custos e racionalizações.}

Atualmente o CD trabalha com 11.000 clientes, que realizaram algum tipo de compra nos últimos quatro meses, cerca de 70\% deles localizados no Estado de São Paulo e os outros $30 \%$ em Minas Gerais, principalmente no sul do Estado. Em média, há o atendimento de 920 clientes/dia, que ocorre de segunda a sábado, onde para cada cliente são respeitadas as restrições de dia e janela de atendimento. A empresa conta ainda com dois pontos de Transbordo, localizados em Araraquara-SP e Vinhedo-SP, que recebem cargas consolidadas do $\mathrm{CD}$ em veículos maiores e as distribuem em veículos menores, para realizar a entrega aos clientes. Para o processo de abastecimento do $\mathrm{CD}$, os produtos são coletados de diversos fornecedores, localizados principalmente nos Estados de Minas Gerais, Rio de Janeiro e São Paulo. O grupo conta com uma frota composta por 82 veículos próprios e 7 veículos terceirizados (que atendem a região do Vale do Paraíba), terceirizando ainda uma grande parte dos cavalos mecânicos e carretas que participam do processo de transferência de produtos.

A Figura 1 apresenta a estrutura organizacional da Cadeia de Suprimentos da empresa. Os setores em destaque foram os que tiveram funcionários entrevistados, utilizando-se a técnica de entrevistas semi-estruturadas. Os entrevistados foram divididos em três grupos. O grupo 1 (encarregado de roteirização e encarregado do PCL), que ajudou na caracterização do cenário e na indicação dos demais entrevistados, o grupo 2 (o gerente, o encarregado de transportes e o auxiliar de roteirização) e o grupo 3 (auxiliar de expedição, alguns motoristas e ajudantes, o gerente e o encarregado de vendas e o encarregado do serviço de atendimento ao cliente, SAC). Esta divisão procurou facilitar as entrevistas dentro dos gru- 
pos e assim abordar todos os termos usados por esses grupos. Além das entrevistas, foram utilizadas ainda como fontes de dados a documentação, registros em arquivos e observação direta, base para que se obtivessem as evidências encontradas no processo, descritas no próximo tópico.

\section{EVIDÊNCIAS DO CASO}

As compras iniciam a movimentação e armazenagem dos produtos, que posteriormente são enviados aos clientes conforme seus pedidos. Após as compras, os compradores informam ao departamento de transportes, via e-mail, quando (data - previsão e tolerância máxima para retirada), onde (fornecedor, endereço do fornecedor, referência e cidade) e o que coletar (produtos, especificações dos produtos, peso, volume). A partir desta comunicação o departamento de transporte é responsável por realizar a programação do veículo para buscar os produtos. Esta programação e retirada do produto no fornecedor é denominada coleta. Para atender os diversos clientes da empresa, a distribuição física conta com uma logística baseada no pólo/central, ou seja, concentra os produtos recebidos dos fornecedores no CD de Poços de Caldas e, a partir deste CD, distribui os produtos para as unidades operacionais (UO) e/ou clientes. Estas UO são classificadas na empresa como pontos de transbordo. A Figura 2 exemplifica esta situação.

A empresa possui operações distintas de coleta e entrega na distribuição física. A maior parte das coletas da empresa corresponde a um par "origem-destino", ou seja, sistema um-para-um, onde um único fornecedor completa a carga do veículo. A empresa atualmente possui em seu cadastro 4.100 fornecedores, que estão presentes em vários Estados e cidades distribuídas pelo Brasil. Diante desta quantidade e de sua distribuição, muitas vezes os veículos da empresa não conseguem atender a demanda, o que leva à terceirização de veículos para trabalhar com as cargas excedentes. De maneira simplificada, a Figura 3 mostra o fluxograma da operação de coleta.

Com relação à movimentação e descarga dos produtos, a maior parte dos fornecedores trabalha com cargas paletizadas, através de paletes padrão. Contudo, existem fornecedores que possuem cargas fracionadas, o que é ruim para a empresa, essencialmente pelo fato de essas cargas fracionadas aumentarem o tempo médio de descarregamento, já que se faz necessário um trabalho adicional de montagem dos paletes para a armazenagem dos produtos. Já para as entregas, a empresa é responsável pela distribuição

Figura 1: Representação da estrutura organizacional da Cadeia de Suprimentos da empresa.

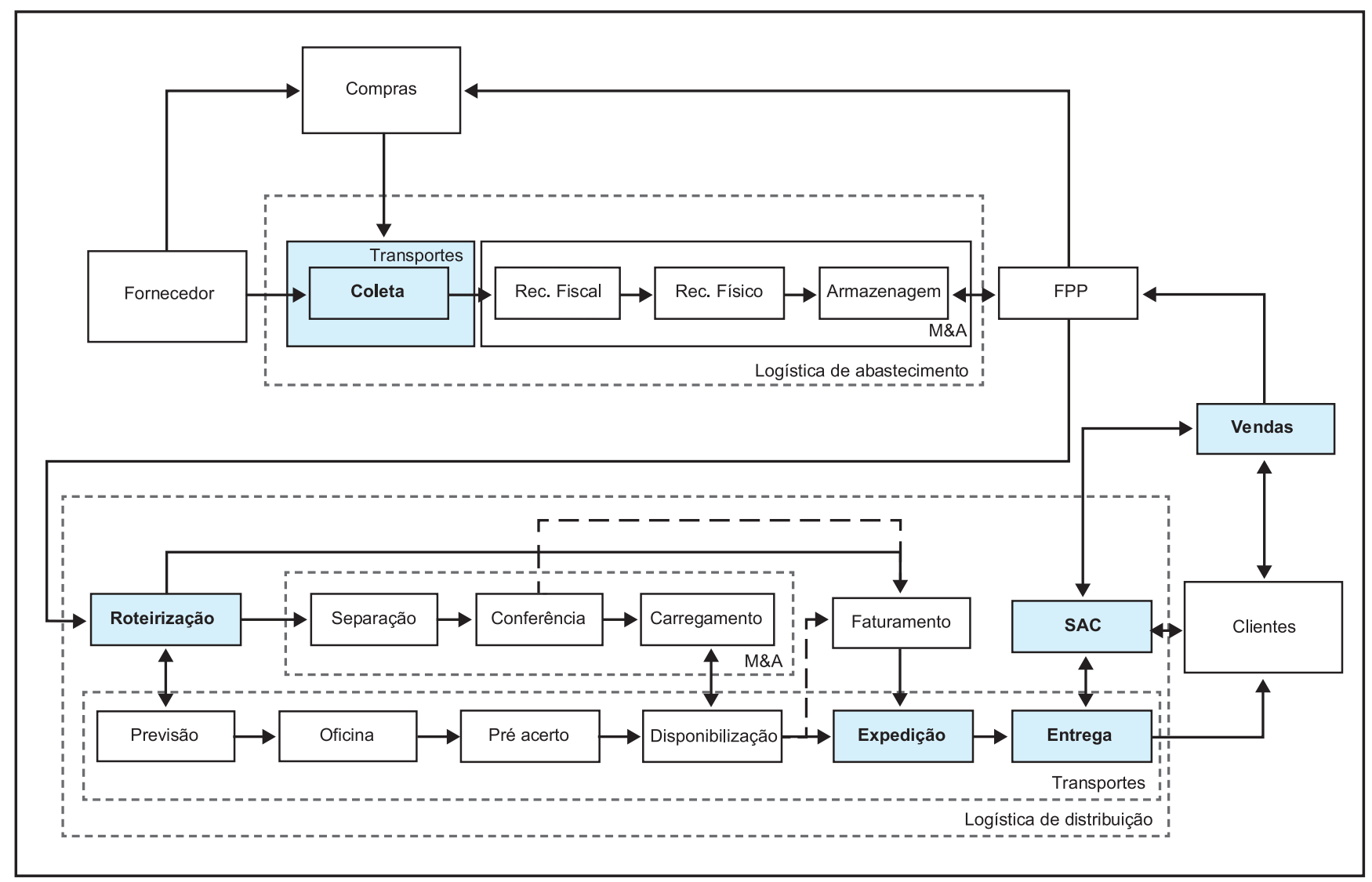


de diversos produtos em diferentes embalagens de vendas, como caixas fechadas de óleo, sal, sabão em pedra (denominadas na empresa de pesados), produtos leves como o papel higiênico, lenços de papel (denominados de levezas) e unidades fracionadas. A Figura 4 apresenta o fluxograma do processo de entrega.
A atividade de formação de carga afeta diretamente a entrega dos produtos, seja no horário de saída dos veículos ou na distribuição efetiva das mercadorias nas entregas, pois as diferentes embalagens de venda apresentam dificuldades para a separação e acomodação dos produtos nos veículos. Para os produtos pesados e levezas, há a separação dos clien-

Figura 2: Esquema de distribuição da empresa.

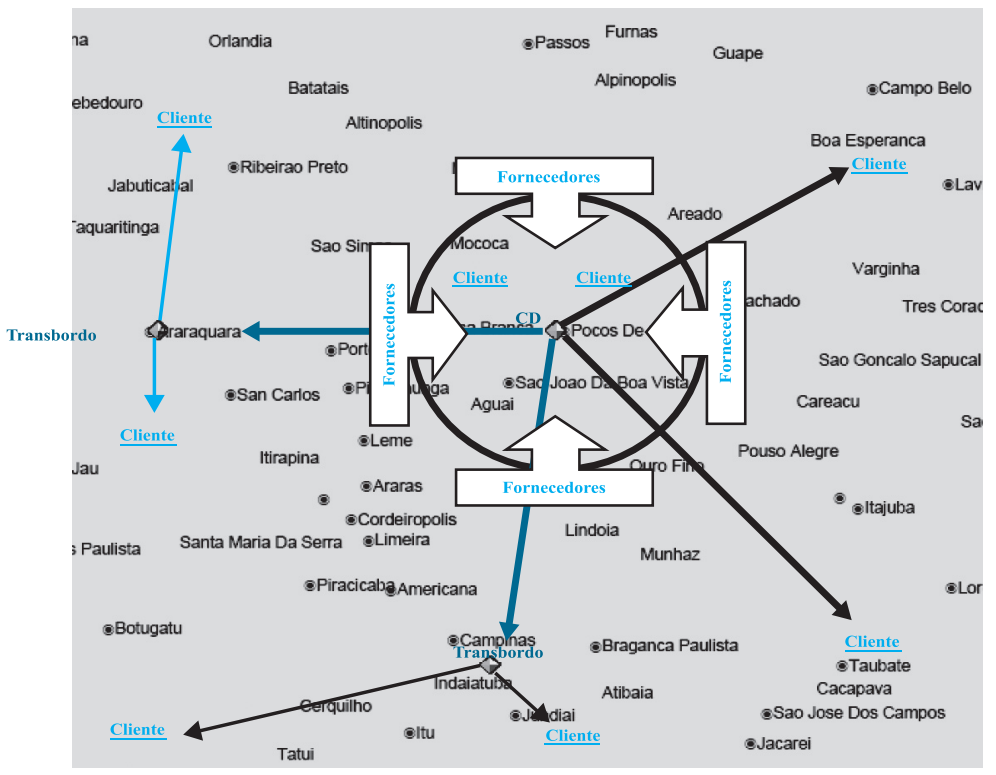

Figura 3: Fluxograma de abastecimento da empresa.

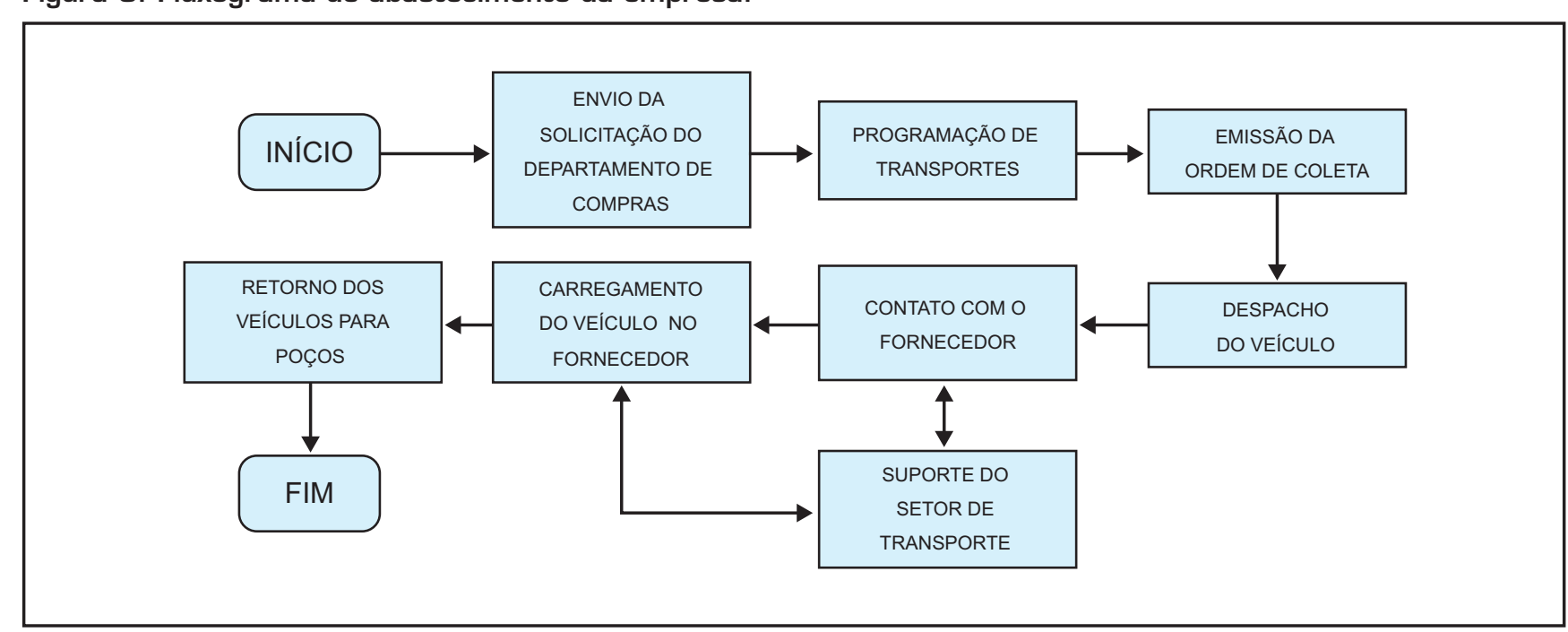


tes de acordo com o seqüencial de entrega, onde os paletes são formados por caixas em função da distribuição imposta para a entrega dos clientes. Já os produtos fracionados são agrupados nas caixas plásticas. A Figura 5 exemplifica a distribuição dos paletes e das caixas plásticas dentro dos veículos.

Nas entregas, os veículos seguem uma seqüência, onde sua primeira entrega será efetuada a partir do roteiro criado pela roteirização e na alocação dos paletes no carregamento, ou seja, nos paletes da parte de traz da carroceria (ver
Figura 5) estão as primeiras entregas. Os motoristas acompanhados de seus ajudantes chegam ao cliente identificado no roteiro, apresentam a nota fiscal e, após a confirmação do cliente, realizam a entrega dos produtos. Enquanto o ajudante separa e leva as mercadorias fracionadas, o motorista começa a separar os produtos em caixa (pesados e levezas) presentes nos paletes. Estes produtos são então conferidos com o cliente, que realiza o pagamento da mercadoria e a assinatura dos comprovantes de recebimento (nota fiscal e boletos).

Figura 4: Fluxograma de distribuição da empresa.

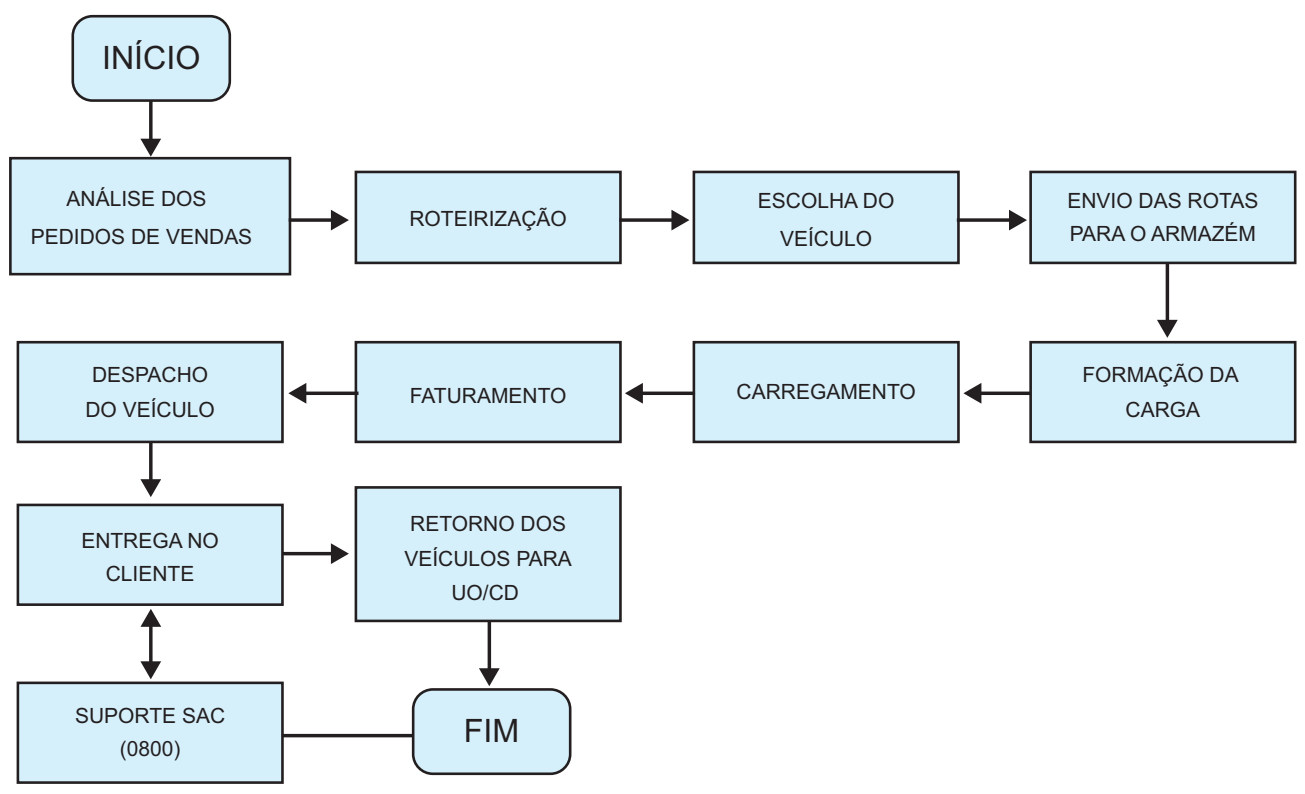

Figura 5: Alocação de carga no veículo de entrega.

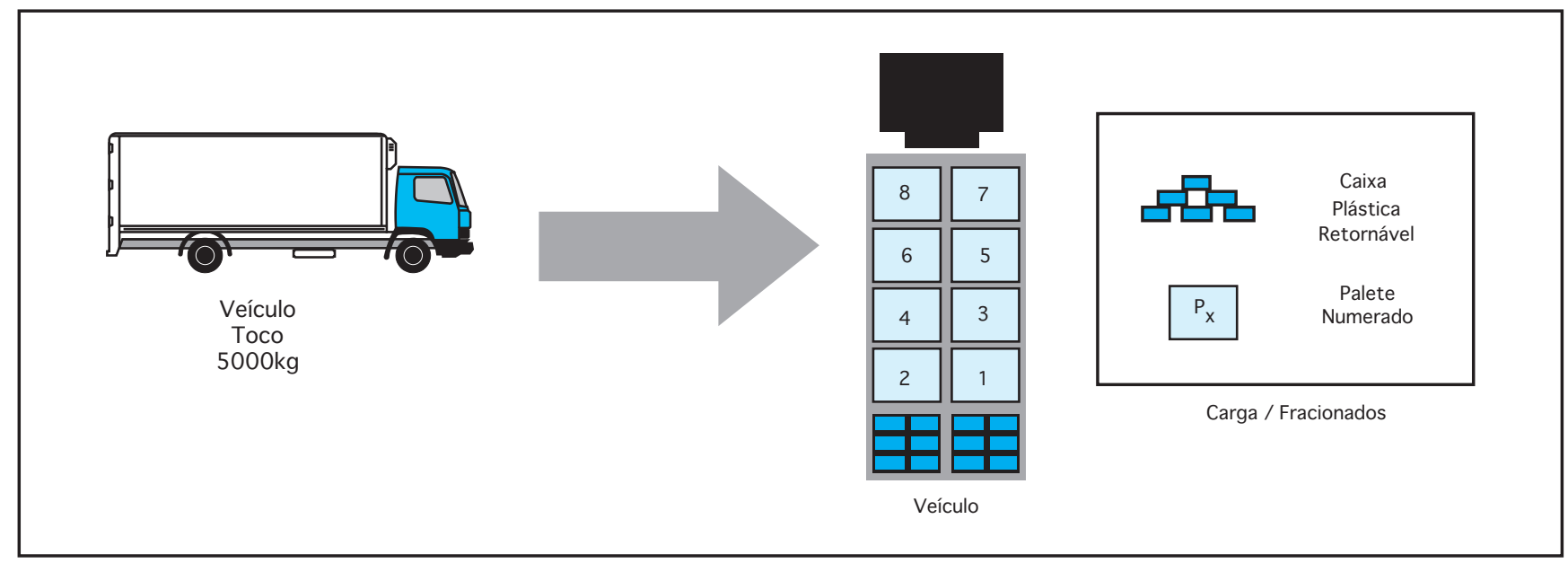


Todos os problemas que os motoristas tenham dentro do intervalo de encontrar o estabelecimento, ficar na fila de espera dos clientes, deixar os produtos e receber os comprovantes devem ser comunicados ao serviço de atendimento ao consumidor (SAC) do atacadista. De forma geral, o SAC apresenta-se como principal canal de comunicação entre a empresa, motoristas e clientes. Este setor é responsável pela comunicação e manutenção das informações referentes aos clientes.

Muitas vezes os problemas que ocorrem nas entregas geram atrasos ou devoluções de mercadorias, no cliente ou no restante das entregas. Nesta condição, os motoristas juntamente com o SAC verificam se há outros clientes para serem atendidos na mesma cidade, se há a possibilidade de ir para outra cidade e depois voltar ou ainda agendar uma reentrega. No entanto, na maior parte das vezes os motoristas ficam parados por várias horas na fila de espera de recebimento ou pagamento.

As informações dos processos de entrega e coleta são acompanhadas pelo gerente de transportes, que analisa todas as evidências e ocorrências citadas pelos vendedores, motoristas, SAC e/ou setor de roteirização. Todas as informações deste histórico foram dimensionadas nos setores para afetarem os indicadores de produtividade, que compõem a parte variável do salário dos motoristas.

\section{Roteirização}

O processo de roteirização está presente somente para as rotas de entrega. Nestas rotas, o processo começa a partir dos pedidos processados e armazenados no sistema corporativo da empresa. Este processamento ocorre várias vezes ao dia, sendo limitado pelos horários de corte (processo que não permite a entrada do pedido fora do horário estipulado), às 19:00, às 19:30 e às 20:00, dependendo da região de atendimento. Após os horários de corte os pedidos não são incluídos na roteirização daquele dia.

$\mathrm{O}$ roteirista então analisa a massa de pedidos e clientes. Caso o cliente esteja realizando sua primeira compra, o servidor aponta este cliente em um relatório chamado de "clientes sem quadrícula". A quadrícula representa a menor divisão espacial existente dentro do software de roteirização (Networks Routing - NR). O roteirista então analisa a praça deste cliente e o coloca em uma quadrícula. Se não existir, é necessário criar uma nova quadrícula, a partir dos dados de sua região, praça, bairro e acessos viários. Qualquer problema no cadastramento dos clientes, seja no cadastro da empresa ou no cadastro da roteirização (quadrícula) trará impactos nas entregas, que poderão ocorrer em estabelecimentos errados, bairros errados ou até mesmo em cidades erradas.

A partir deste ponto o software começa a agrupar os pedidos dos clientes nas melhores rotas, de acordo com os parâmetros adotados. O roteirista analisa então os veículos disponíveis (tipos e quantidades) existentes na empresa para finalizar as rotas. De posse desta informação, as rotas são analisadas pelo roteirista, considerando o dimensionamento dos recursos (verifica-se volume, peso, quantidade de entregas e tempo total das rotas). É importante ressaltar que algumas rotas são modificadas manualmente pelo roteirista. As mudanças são feitas em sua forma, quantidade de entregas e outros, sendo necessárias em algumas rotas, pois por alguma razão as condições criadas pelo software para elas não correspondem a rotas reais e os motoristas não conseguiriam cumpri-las. Existem casos em que o software associa a entrega a dois clientes em cidades diferentes, como se eles estivessem em bairros próximos, ou, ainda, a rota possui várias voltas ao redor de determinados clientes ou agrupamentos que visivelmente podem ser corrigidas. Observa-se que estas rotas modificadas não são documentadas, ficando atreladas à experiência do roteirista. A atividade de programação do veículo segue uma etapa posterior à roteirização, executada pelo setor de despacho dos veículos, após toda verificação e confirmação da chegada ou liberação dos veículos.

\section{experiência do roteirista ainda é
considerada como fator decisivo na formação da rota.}

Em condições normais de trabalho, as rotas elaboradas são planejadas para atender os clientes no menor tempo possível: $60 \%$ dos pedidos são entregues em 24 horas, $30 \%$ são atendidos em até 48 horas e 10\% em no máximo 72 horas. Para esse perfil de entregas, a empresa apresenta um alto custo operacional, sendo que muitas vezes o roteirista não racionaliza as rotas em função desta diretriz (menor tempo de entrega) imposta pela empresa. Os relatórios gerenciais apontam que o departamento de transporte responde por $85 \%$ dos custos de logística e totaliza $4,2 \%$ do faturamento médio mensal.

\section{Software de roteirização}

A empresa começou em 1986 a trabalhar com o software de roteirização chamado Trucks, que operava em ambiente DOS. Segundo Melo e Filho (2001), o Trucks é um dos softwares mais antigos existentes no mercado nacional, sendo utilizado desde a década de 1980, e foi o que possuiu o maior número de usuários. Aúltima versão utilizada pela empresa é o Networks Routing (NR), versão 7.2.1, que possui recursos que facilitam a visualização dos mapas e redes, e ainda várias parametrizações para clientes, pedidos e/ou rotas. 
O custo de aquisição do software foi relativamente alto, inclusos aí os custos de manutenção anual, segundo as informações da empresa. Para que um profissional da empresa esteja apto para a roteirização é necessário um treinamento de no mínimo seis meses. A empresa recomenda dois funcionários (encarregado + auxiliar) para a roteirização. O primeiro realiza todas as atualizações e desenvolvimentos na malha e o segundo opera o sistema e realiza a roteirização diária.

A malha viária é atualizada manualmente quando necessário, e o cliente é alocado perto de uma quadrícula mais próxima de suas especificações. Os mapas atuais são digitais com padrão MapInfo, incluindo vários recursos, como a geocodificação em função dos CEPs, endereços ou cidades. O software apresenta uma interface bastante amigável ao usuário, através de janelas com informações sobre as Praças ou locais (Location), Pedidos (Order), Rede (Network), Planejamento (Planning) e Rotas (Route).

\section{Informações do processo}

Todos os entrevistados concordam quanto à importância de indicadores para a empresa e para os departamentos e setores. Os principais recursos usados na coordenação do departamento de transporte são os indicadores, arquivos e relatórios do setor. Tem-se ainda o relato do uso de informações das ferramentas e software de trabalho, como o $N R$, rastreadores, sistema de gerenciamento e manutenção da frota, tacógrafos e, em muitos casos, através dos funcionários responsáveis por determinadas atividades. Estas informações são usadas para ações de melhoria e/ou tomada de decisões gerenciais.

\section{Análise dos fatores envolvidos no processo}

A partir da análise das fontes de evidências foi possível listar alguns fatores que afetam direta ou indiretamente a distribuição física e/ou o processo de roteirização da empresa. A Tabela 1 relaciona estes fatores aos entrevistados que relataram o fator considerando o processo da empresa. É necessário ressaltar que estes fatores não estão ordenados por grau de importância.

Os entrevistados foram representados nesta tabela por letras: $a$ - encarregado de roteirização, $b$ - encarregado de PCL, $\mathrm{c}$ - gerente de transportes, $\mathrm{d}$ - encarregado de transportes, e - auxiliar de roteirização, $\mathrm{f}$ - auxiliar de expedição, $\mathrm{g}$ - motoristas, $\mathrm{h}$ - ajudantes, $\mathrm{i}$ - gerente de vendas, $\mathrm{j}$ - encarregado de vendas, $\mathrm{k}$ - encarregado de SAC .

A Tabela 2 apresenta um resumo de algumas vantagens e desvantagens de cada um dos fatores descritos a partir das fontes de evidências. Seguem-se algumas considerações a respeito.

- A relação entre os fatores fracionamento, peso e volume. Estes fatores podem ser trabalhados visando uma melhor alocação dos produtos nos veículos e rotas, alcançando por conseqüência um melhor aproveitamento dos veículos e a redução do número de avarias e danos nos produtos pela movimentação dos mesmos nas entregas. Estes fatores alteram diretamente as características de restrição de capacidade e tipos de veículos.

- Com relação à carga e descarga, uma mudança operacional pode ocasionar problemas no processo de roteirização. Recomendam-se estudos sobre o tempo de carga e descarga $\mathrm{x}$ cargas separadas na entrega, atualizando os

Tabela 1: Fatores relacionados ao processo x entrevistados.

\begin{tabular}{|c|c|c|c|c|c|c|c|c|c|c|c|}
\hline ENTREVISTADOS & $\mathbf{A}$ & $\mathbf{B}$ & $\mathbf{G}$ & $\mathbf{D}$ & $\mathbf{E}$ & $\mathbf{F}$ & $\mathbf{G}$ & $\mathbf{H}$ & $\mathbf{I}$ & $\mathbf{J}$ & $\mathbf{K}$ \\
\hline \multicolumn{12}{|l|}{ Fracionamento de produtos } \\
\hline \multicolumn{12}{|l|}{ Relação Peso/Volume x valor agregado } \\
\hline \multicolumn{12}{|l|}{ Comunicação } \\
\hline \multicolumn{12}{|l|}{ Programação das coletas $x$ prazo máximo de retirada } \\
\hline \multicolumn{12}{|l|}{ Falta de Sinergia entre as cargas de entrega e as coletas } \\
\hline \multicolumn{12}{|l|}{ Efeito da paletização no processo de distribuição } \\
\hline \multicolumn{12}{|l|}{ Processo de carga e descarga } \\
\hline \multicolumn{12}{|l|}{ Parametrizações do software de roteirização } \\
\hline \multicolumn{12}{|l|}{ Média de clientes atendidos por dia } \\
\hline \multicolumn{12}{|l|}{ Sistema de zoneamento da empresa } \\
\hline \multicolumn{12}{|l|}{ Formas de pagamento } \\
\hline \multicolumn{12}{|l|}{ Atendimento dos pedidos na empresa } \\
\hline \multicolumn{12}{|l|}{ Filas de espera nos clientes } \\
\hline Falta de indicadores & & & & & & & & & & & \\
\hline
\end{tabular}


Tabela 2: Resumo dos fatores descritos nas fontes de evidências.

\begin{tabular}{|c|c|c|}
\hline FATORES & VANTAGENS & DESVANTAGENS \\
\hline $\begin{array}{l}\text { Fracionamento de } \\
\text { produtos }\end{array}$ & $\begin{array}{l}\text { O cliente pode comprar em } \\
\text { menores quantidades. }\end{array}$ & $\begin{array}{l}\text { Problemas Operacionais: na separação, alocação e } \\
\text { movimentação dos produtos; } \\
\text { Aumento do tempo de descarga; } \\
\text { Possibilidade de danificar os produtos; } \\
\text { Diminuição do espaço útil pela utilização de caixas plásticas. }\end{array}$ \\
\hline $\begin{array}{l}\text { Relação Peso / Volume } x \\
\text { valor agregado }\end{array}$ & $\begin{array}{l}\text { Esta relação pode ser } \\
\text { usada como referência de } \\
\text { utilização dos veículos. }\end{array}$ & $\begin{array}{l}\text { Problemas Operacionais: na separação e formação da carga } \\
\text { pelo depósito; } \\
\text { Problemas no faturamento dos produtos; } \\
\text { Multas por excesso de peso; } \\
\text { Problemas pelo não balanceamento das cargas; } \\
\text { Sub ou superlotação dos veículos; } \\
\text { Atrasos. }\end{array}$ \\
\hline Comunicação & $\begin{array}{l}\text { As informações podem ser } \\
\text { agrupadas em um banco } \\
\text { de dados, gerando um } \\
\text { histórico para a empresa. }\end{array}$ & $\begin{array}{l}\text { Programação incorreta de veículos; } \\
\text { Atrasos de entregas; } \\
\text { Gastos desnecessários. }\end{array}$ \\
\hline $\begin{array}{l}\text { Programação das coletas } \\
\text { x prazo máximo de } \\
\text { retirada }\end{array}$ & \multirow{2}{*}{$\begin{array}{l}\text { De fácil resolução; } \\
\text { Possibilita o aumento } \\
\text { do sincronismo das } \\
\text { operações. }\end{array}$} & \multirow{2}{*}{$\begin{array}{l}\text { Comunicação entre os setores com possibilidade de erros; } \\
\text { Falta de um sistema de validação do pedido de coleta; } \\
\text { Contratações de transporte em caráter emergencial; }\end{array}$} \\
\hline $\begin{array}{l}\text { Falta de Sinergia entre as } \\
\text { cargas de entrega e as } \\
\text { coletas }\end{array}$ & & \\
\hline $\begin{array}{l}\text { Parametrizações do } \\
\text { software de roteirização }\end{array}$ & $\begin{array}{l}\text { Recursos do Software; } \\
\text { Interface amigável. }\end{array}$ & $\begin{array}{l}\text { Parâmetros do software não conhecidos pelos usuários; } \\
\text { Treinamento inicial superficial; } \\
\text { Algoritmo de resolução não conhecido; } \\
\text { Software de difícil calibragem. }\end{array}$ \\
\hline $\begin{array}{l}\text { Sistema de zoneamento } \\
\text { da empresa }\end{array}$ & $\begin{array}{l}\text { Referência de trabalho; } \\
\text { Fácil manutenção dos } \\
\text { pontos de coordenadas } \\
\text { geográficas. }\end{array}$ & $\begin{array}{l}\text { Quebra de área em função de acessos rodoviários e relevo; } \\
\text { Sistemática empírica de divisão das zonas. } \\
\text { Agrupamento de vários pontos em uma mesma coordenada } \\
\text { geográfica; } \\
\text { Problemas ao mensurar tempos reais de atendimento; } \\
\text { Grande divergência entre a quilometragem planejada e a } \\
\text { rodada (real). }\end{array}$ \\
\hline $\begin{array}{l}\text { Média de clientes } \\
\text { atendidos por dia }\end{array}$ & Referência de trabalho. & $\begin{array}{l}\text { Falta de documentação sobre o cálculo das médias; } \\
\text { Variação na quantidade de pontos atendidos. }\end{array}$ \\
\hline Formas de pagamento & $\begin{array}{l}\text { Grande variedade de forma } \\
\text { de pagamento. }\end{array}$ & $\begin{array}{l}\text { Atrasos } \\
\text { Devoluções } \\
\text { Avarias }\end{array}$ \\
\hline $\begin{array}{l}\text { Atendimento dos pedidos } \\
\text { na empresa }\end{array}$ & $\begin{array}{l}\text { Tempo de atendimento dos } \\
\text { pedidos. }\end{array}$ & $\begin{array}{l}\text { Subutilização dos recursos; } \\
\text { Aumento dos gastos. }\end{array}$ \\
\hline $\begin{array}{l}\text { Filas de espera nos } \\
\text { clientes }\end{array}$ & --- & Prejudica o planejamento e a programação dos veículos. \\
\hline Falta de indicadores & --- & Dificulta o gerenciamento. \\
\hline
\end{tabular}


tempos médios usados no planejamento das rotas.

- A paletização é algo indispensável na carga e descarga dos produtos coletados nos fornecedores. Porém, para as entregas é necessária uma revisão sobre este procedimento. Sem a paletização, os espaços úteis de carga dos veículos podem ser melhor aproveitados. Observa-se que a paletização afeta o fator carga e descarga, que por sua vez sofre influência dos fatores peso, volume e fracionamento. A relação entre estes fatores está associada às restrições de capacidade dos veículos, criando problemas aos tempos da rota, programação de pessoal e outros.

- Para os pedidos enviados depois do horário de corte, nota-se a ocorrência de problemas operacionais. Dentre eles, rotas com custos elevados, devido a valores, pesos e volumes bastante baixos e veículos subutilizados.

- A comunicação é um outro fator de problema na empresa, que pode ser melhorado. Este fator possui participação direta no processo de roteirização e programação. É importante ressaltar que de nada adianta ter muita informação, ela precisa ser estruturada e monitorada no fluxo para que se tenha o resultado esperado.

- Um ponto ressaltado pelos entrevistados e bastante discutido com o pesquisador foi a não roteirização das coletas. A partir dos dados gerados nesta possível roteirização haveria um aumento na precisão das informações e, com isto, a empresa teria condições de realizar de maneira mais eficiente a sinergia de cargas em nível operacional. las e o não conhecimento das parametrizações do software podem ocasionar manutenções manuais constantes nas rotas. As mudanças das rotas pelo conhecimento dos roteiristas podem ocasionar problemas futuros em possíveis mudanças de profissionais. Com isto, muitas vezes não são consideradas todas as características e restrições, não permitindo que o problema seja racionalizado.

- Não há um conjunto adequado de indicadores operacionais para analisar o desempenho das rotas criadas. Existe a preocupação do roteirista quanto à relação peso x volume $\mathrm{x}$ valor, porém não é analisada diariamente como fator limitante de formação de rotas. O setor de roteirização e o departamento de transportes precisam acompanhar indicadores operacionais, para que possam ter uma referência de trabalho, principalmente da qualidade de rota, e usá-los no benchmarking. Essas informações são cruciais no planejamento da distribuição física e das rotas.

\section{CONCLUSÕES}

O objetivo deste trabalho foi analisar a distribuição física em uma empresa do setor atacadista, com especial atenção ao seu processo de roteirização e programação de veículos. Para tanto, foi realizado um estudo de caso em um grande atacadista, localizado na região Sul de Minas Gerais, no qual se procurou relacionar os aspectos práticos que cercam estas rotinas operacionais, baseadas na literatura técnica especializada.

Foi possível identificar no processo da empresa que a teoria e a prática, no que tange à idéia de otimização da roteirização e programação, ainda estão distantes. O escopo da empresa é o atendimento no menor prazo, não se preocupando com os custos em um primeiro instante. Portanto, ainda falta definir claramente qual é o melhor método

- O software da empresa apresenta várias parametrizações, porém os roteiristas não conhecem as implicações destas nas rotas. Este problema precisaria ser seriamente atacado para que o potencial do software fosse utilizado em sua totalidade.

- O esforço por tempos de entrega baixos, muitas vezes utilizado como fator ganhador de pedido, deve ser analisado considerando o custo de transporte.

- A quantidade de clientes e os sistemas de zoneamento estão diretamente ligados, onde uma melhor distribuição dos clientes em zonas ótimas e com padrões bem definidos pode trazer ganhos para a empresa. Observa-se que as divisões chamadas de quadrículas geram distorções nas quilometragens rodadas, não permitindo que os roteiristas usem as quilometragens reais para se basearem quanto aos custos das rotas. É importante evidenciar que as quadrícu- de trabalho, revisando esta diretriz de atendimento, onde a roteirização da empresa deve rever os conceitos e funções aplicadas ao setor. Deste modo, o setor de roteirização deve trabalhar para se aproximar da proposta de racionalização das rotas criadas, potencializando o uso das ferramentas de trabalho, software e com a criação de indicadores de acompanhamento.

Como conclusão geral, pode-se afirmar que a empresa, apesar de utilizar diversos conceitos e ferramentas de apoio em seu processo de distribuição física, especialmente um software robusto de roteirização, ainda é refém da falta de informações em processos operacionais tecnicamente simples (como as distâncias viárias exatas entre os clientes). Como conseqüência, o processo acaba por ser excessivamente dependente do fator humano em diversas etapas, ou seja, da experiência prática do profissional envolvido. No 
entanto, na visão da empresa, ela trabalha com o ambiente ideal de distribuição física e roteirização, pois atende as diretrizes impostas pela relação diretoria/clientes/mercado, preocupando-se muito mais com a satisfação dos clientes do que com os custos de distribuição.

Finalmente, acredita-se que esse trabalho possa contribuir para melhorar a compreensão dos problemas logísticos de outras empresas, similares ou não à que foi aqui abordada, na medida em que apresenta como diversos problemas simples do ponto de vista tecnológico, quando não atacados corretamente em um problema real, podem culminar com soluções distantes da ótima, mesmo quando, por exemplo, softwares robustos de roteirização são utilizados. Questões como os parâmetros de localização geográfica dos clientes (atribuição das quadrículas no caso da empresa em questão), quando não corretamente utilizados, comprometem claramente a qualidade das soluções obtidas no software roteirizador em particular, e na distribuição física da empresa em geral. Considera-se igualmente importante que o conhecimento empírico dos profissionais e o conhecimento teórico dos acadêmicos sejam combinados e divulgados, para que os problemas aqui identificados possam ser evitados em outras empresas.

\section{Artigo recebido em 21/06/2006 Aprovado para publicação em 27/02/2007}

\section{neferências}

ASSAD, A. A. Modeling and Implementation Issues in Vehicle Routing. In: Vehicle Routing: Methods and Studies, edited by: Golden, B. L; Assad, A. A. v. 16, p. 127148, second impression, 1991.

BALLOU, R. H. Gerenciamento da Cadeia de Suplementos: Planejamento, Organização e Logística Empresarial. Trad. Elias Pereira. Porto Alegre: Bookman, 2001.

BERMAN, B. Marketing Channels. John Willey \& Sons, 663 p. 1996.

BODIN, L. D.; GOLDEN, B.; ASSAD, A.; BALL, M. Routing and Scheduling of vehicles and crews: The state of the art. Computers and Operations Research, v. 10, n. 2, 1983.

BONOMA, T. V. Case Research in Marketing: Opportunities, Problems and Process. Journal of Marketing Research, v. 22, p. 203. May, 1985.

BOSE, R. de C. A. Modelos de Roteirização e Programação de entregas em redes de transportes. 1990. Dissertação (Mestrado) - Escola Politécnica da Universidade de São Paulo, Departamento de Engenharia de Transportes, São Paulo. 171 p.

Botelho, L. G. Um Método para o Planejamento Operacional da Distribuição: Aplicação para casos com Abastecimento de Granéis Líquidos. 2003. Dissertação (Mestrado) - Programa de Pós-Graduação em Logística Empresarial, PUC, Rio de Janeiro. 100 p.

BOWERSOX, Donald J.; CLOSS, David J. Logística Empresarial: o processo de integração da cadeia de suprimento. Tradução da Equipe do Centro de Estudos em Logística, Adalberto Ferreira das Neves; Coordenação da revisão técnica Paulo Fernando Fleury, César Lavalle. São Paulo: Atlas, 2001.

BOWERSOX, D.J.; COOPER, M. B. Strategic Marketing Channel Management. McGraw-Hill: New York, 1992.

CHIH, W. Y. Influência dos Custos Fixos e Variáveis na Roteirização de Frotas de Veículos com Capacidades Variadas. 1987. Dissertação (Mestrado) - Escola Politécnica da Universidade de São Paulo, Departamento de Engenharia de Transportes, São Paulo. 128 p.

COUTO, P. T. B. Resolução de Problemas de Transporte Rodoviário de Carga Utilizando Programação Inteira. 2004. Dissertação (Mestrado) - Programa de Pós-Graduação em Engenharia Elétrica, PUC, Rio de Janeiro, 81 p.

CUNHA, C. B. Aspectos Práticos da Aplicação de Modelos de Roteirização de Veículos a Problemas Reais. Transportes, v. 8, n. 2 , p. $51-74,2000$

CUNHA, C. B. Uma Contribuição para o Problema de Roteirização de Veículos Com Restrições Operacionais. 1997. Tese (Doutorado) - Escola Politécnica da Universidade de São Paulo, Departamento de Engenharia de Transportes, São Paulo. 222 p.

DEMARIA, M. O Operador de Transporte Multimodal como Fator de Otimização da Logística. 2004. Dissertação (Mestrado) - Programa de Pós-Graduação em Engenharia de Produção e Sistemas, UFSC, Florianópolis. 87 p.
DINIZ, U. L. Dimensionamento de frotas de veículos para apoio a maquinário de usinas sucroalcooleiras. 2000. Dissertação (Mestrado) - Escola de Engenharia de São Carlos, USP, São Carlos. 163 p.

EISENHARDT, K. M. Building Theories from Case Study Research. Academic of Management Review, v. 14, n. 4, p. 53250, 1989.

ENOMOTO, L. M. Análise da distribuição física e roteirização em um atacadista do Sul de Minas Gerais. 2005. Dissertação (Mestrado) - Programa de Pós-Graduação em Engenharia de Produção, Universidade Federal de Itajubá - UNIFEI, Itajubá. 141 p.

GALVÃO, L. C. Dimensionamento de Sistemas de Distribuição através do Diagrama Multiplicativo de Voronoi com Pesos. 2003. Tese (Doutorado) - Programa de PósGraduação em Engenharia de Produção e Sistemas, UFSC, Florianópolis. 175 p.

LAPORTE, G.; GENDREAU, M.; POTVIN, J. Y.; SEMET, F. Classical and Modern Heuristics for the Vehicle Routing Problem. International Transactions in Operational Research, v. 7, n. 4/5, p. 285$300,2000$.

MELO, A. C. da S.; FILHO, V. J. M. F. Sistemas de Roteirização e Programação de Veículos. Pesquisa Operacional, v. 21, n. 2, p. 223-232, julho a dezembro de 2001.

NARUO, M. K. O Estudo do consórcio entre municípios de pequeno porte para disposição final de Resíduos Sólidos Urbanos, utilizan- do Sistemas de Informação Geográficos. 2003. Dissertação (Mestrado) - Escola de Engenharia de São Carlos, USP, São Carlos. 283 p.

NEVES. M. F. Um Modelo para Planejamento de Canais de Distribuição no Setor de Alimentos. 1999. Tese (Doutorado) - Faculdade de Economia, Administração e Contabilidade, USP, São Paulo. 297 p.

NOVAES, A. G. Sistemas Logísticos: Transporte, Armazenagem e Distribuição de Produtos. São Paulo: Edgard Bluncher, 1989.

NOVAES, A. G. Logística e Gerenciamento da Cadeia de Distribuição. Rio de Janeiro Elsevier - Editora Campus, 2004.

PELIZARO, C. Avaliação de Desempenho do Algoritmo de um Programa Comercial para Roteirização de Veículos. 2000 Dissertação (Mestrado) - Escola de Engenharia de São Carlos, USP, São Carlos. 153p.

STERN, L. W.; EL-ANSARY, A. I; COUGHLAN, A. T. Marketing Channels. Prentice-Hall, Upper Saddle River, NJ. $5^{\text {th }}$ edition, 576 p., 1996.

VALENTE, A. M.; PASSAGLIA, E.; NOVAES, A. G. Gerenciamento de Transporte e Frota. São Paulo, Editora Pioneira, 2003.

VIEIRA, A. B. Roteirização de ônibus urbano: escolha de um método para as grandes cidades brasileiras. 1999. Dissertação (Mestrado) - Escola de Engenharia de São Carlos, USP, São Carlos. 148 p. 


\section{- Agradecimentos}

Os autores agradecem à CAPES - Coordenação de Aperfeiçoamento de Pessoal de Nível Superior - e à FAPEMIG - Fundação de Amparo à Pesquisa de Minas Gerais - pelos auxílios financeiros ao projeto que deu origem a este trabalho.

\section{- Sobre os autores}

\section{Leandro Minoru Enomoto}

Engenheiro de Produção e Mestre em Engenharia de Produção pela Universidade Federal de Itajubá UNIFEI / Instituto de Engenharia de Produção e Gestão

End.: Av. BPS, 1303 - Bairro Pinheirinho - 37502-903 - Itajubá - MG

Tel.: (35) 3629-1296

E-mail:1menomoto@yahoo.com.br

\section{Renato Da Silva Lima}

Engenheiro Civil, Mestre e Doutor em Engenharia de Transportes pela Escola de Engenharia de São Carlos da Universidade de São Paulo (EESC/USP). Pós-Doutorado na Escola de Engenharia da Universidade do Minho, Portugal.

Professor Adjunto do Instituto de Engenharia de Produção e Gestão da Universidade Federal de Itajubá (UNIFEI), atuando na área de Logística e Transportes nos cursos de graduação em Engenharia de Produção e Administração de Empresas, Mestrado em Engenharia de Produção, Especialização em Qualidade \& Produtividade e MBA UNIFEI.

Universidade Federal de Itajubá (UNIFEI)

Instituto de Engenharia de Produção e Gestão

End.: Av. BPS, 1303 - Bairro Pinheirinho - 37502-903 - Itajubá - MG

Tel.: (35) 3629-1296 Fax: (35) 3629-1149

WebPage: www.rslima.unifei.edu.br

E-mail: rslima@unifei.edu.br 